their oxides and, hence, to volatile chelates of the form $\mathrm{ZrO} X_{2}$ (where $X$ is the residue of a fluorinated diketone). It is possible to determine such chelates using the same method and, hence, to estimate zirconium and hafnium in aqueous solution. Work is proceeding upon the determination of zirconium and hafnium in alloys and ores by this procedure.

\section{ACKNOWLEDGMENT}

The authors are indebted to M. J. A. Reade for assistance in mass spectrometry.

RECEIVED for review December 15, 1969. Accepted February 16, 1970.

\title{
Ferrozine-A New Spectrophotometric Reagent for Iron
}

\author{
Lawrence L. Stookey \\ Hach Chemical Company, 713 South Duff Avenue, Ames, Iowa 50010
}

SINCE THE LATTER part of the nineteenth century, organic molecules containing a certain atomic configuration, namely $-\mathrm{N}=\mathrm{C}-\mathrm{C}=\mathrm{N}-$, have been known to react as bidentate ligands with certain metal ions such as ferrous, cuprous, and cobaltous, to give colored complex species $(1-6)$. This effect was first noticed with the ferrous ion (1), and since this complex of a given compound is generally of a more intense color than are those with other ions (7), the atomic configuration in question was given the trivial name of the ferroin group. During the last century, hundreds of compounds containing the ferroin group have been synthesized (7), the majority of which demonstrate the ability to form complexes with the ferrous ion. Most of these complexes are only weakly colored, are unstable under normal physical conditions, or are formed over a very narrow $\mathrm{pH}$ range. A few of these compounds, however, form stable, intensely colored species with the ferrous ion and are, therefore, suitable for the quantitative determination of iron (8). Examples of compounds which have found acceptance for such use are 1,10phenanthroline (9), 4,7-diphenyl-1,10-phenanthroline (10), 2,2'-bipyridine (11), 2,6-bis(2-pyridyl)-pyridine (11), 2,4,6tris(2-pyridyl)-1,3,5-triazine (12), and phenyl 2-pyridyl ketoxime $(13,14)$.

Many of these reagents are the product of difficult and tedious organic syntheses and, hence, are high in cost (14). Although for even the most expensive of these reagents, the cost of a single manual analysis is fairly low, when one considers automated continuous instrumental analysis, a lowcost yet highly sensitive reagent would be desirable, since the cost of maintaining such an analytical instrument with

(1) F. Blau, Monatsh., 19, 666 (1898).

(2) A. Smirnoff, Helv. Chim. Acta, 4, 802 (1921).

(3) L. Tshugaeff, Ber., 39, 3382 (1906).

(4) F. Burstall, J. Chem. Soc., 1938, 1662.

(5) F. Case, J. Amer, Chem. Soc., 68, 2574 (1940).

(6) A. Pinner, Ber., 27, 984 (1894).

(7) A. Schilt, Talanta, 13, 895 (1967).

(8) A. Schilt and W. Hoyle, ANAL. Chem., 39, 114 (1967).

(9) W. Fortune and M. Mellon, IND. ENG. Chem., ANAL. Ed., 10, 60 (1938).

(10) G. Smith, W. McCurdy, and H. Diehl, Analyst, 77, 418 (1952).

(11) M. Moss and M. Mellon, Ind. Eng. Chem., Anal. Ed., 14,862 (1942).

(12) P. Collins, H. Diehl, and G. Smith, ANal. Chem., 31, 1862 (1959).

(13) R. Chernin and E. Simonsen, ibid., 36, 1093 (1964).

(14) H. Diehl and G. Smith, "The Iron Reagents," The G. Frederick Smith Chemical Company, Columbus, Ohio, 1960.

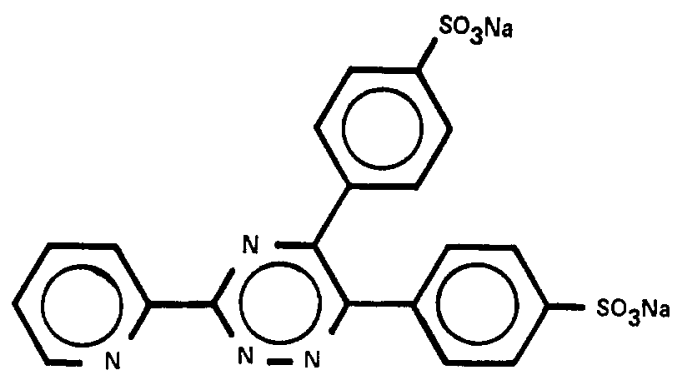

Figure 1. Structure of ferrozine

presently available reagents becomes prohibitive. The purpose of this work, therefore, was the synthesis of a colorimetric reagent for iron which would have a sensitivity comparable to that of the 2,4,6-tris(2-pyridyl)-1,3,5-triazine (commonly known by the acronym TPTZ) now in limited use in automatic analysis (15), but which would also cost substantially less than other reagents commercially available.

Such a reagent was found in the disodium salt of 3-(2pyridyl)-5,6-bis(4-phenylsulfonic acid)-1,2,4-triazine, hereafter referred to as ferrozine (Hach Chemical Co., Catalog No. 2304). This compound reacts with divalent iron to form a stable magenta complex species which is very soluble in water and may be used for the direct determination of iron in water (Figure 1).

\section{EXPERIMENTAL}

Preparation of Ferrozine. The parent compound 3-(2pyridyl)-5,6-diphenyl-1,2,4-triazine was prepared according to Case (16). This compound was subsequently sulfonated and isolated as the disodium salt. The product is a light yellow powder which melts with decomposition above $350{ }^{\circ} \mathrm{C}$ and may be recrystallized from water.

Anal. Calcd for $\mathrm{C}_{20} \mathrm{H}_{12} \mathrm{~N}_{4} \mathrm{~S}_{2} \mathrm{O}_{6} \mathrm{Na}_{2}:$ C, 46.70; N, 10.89; and $S, 12.46$. Found: C, 46.78 and $46.64 ; \mathrm{N}, 10.84$ and 10.89 ; and $S, 12.50$ and 12.58 .

Physical Characteristics of the Ferrous Complex. The visible absorption spectrum of the ferrous complex of ferrozine exhibits a single sharp peak with maximum absorbance at $562 \mathrm{~nm}$. At this wavelength, the molar absorptivity is

(15) J. Dunbar, "Automated Continuous Determination of Total Copper and Iron in Boiler Feedwater," Technicon Symposium on Automated Analytical Chemistry, Technicon Instruments Co. Ltd., Hansworth Lane, Chertsey, Surrey, England, 1965.

(16) F. Case, J. Org. Chem., 30, 931 (1965). 


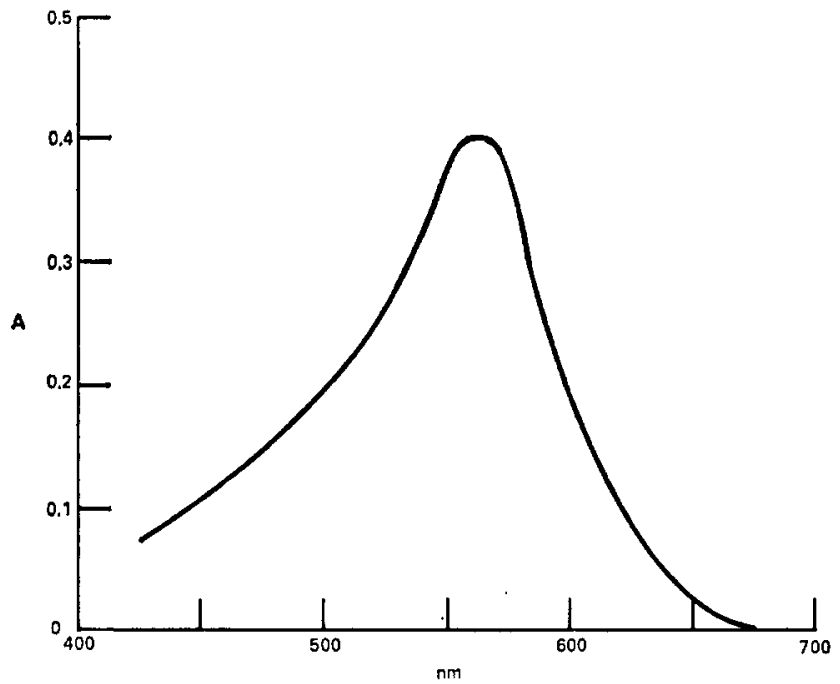

Figure 2. Visible absorption spectrum of ferrous complex of ferrozine

27,900 and the Beer-Lambert law is obeyed to approximately $4 \mathrm{mg} /$ liter of $\mathrm{Fe}$ (Figure 2).

It has been determined by spectrophotometric titration that ferrozine forms the expected tris complex with ferrous iron $(8)$. The end point for the titration of $9 \times 10^{-6}$ mole of ferrozine occurs at $3 \times 10^{-6}$ mole of ferrous ion. The formation constant of the complex is too large to evaluate from this data by conventional methods. Details of the complex structure are given in the discussion (Figure 3 ).

The magenta $\mathrm{Fe}$ (ligand) ${ }_{3}{ }^{2+}$ species will form completely in aqueous solution between the $\mathrm{pH}$ values of 4 and 9 . Once formed between these values, the complex is stable to $1 N$ perchloric acid (Figure 4).

Determination of Iron in Potable Water. Reagents ReQUIRED. Acid Reagent Solution. Dissolve $5.14 \mathrm{~g}$ of ferrozine and $100 \mathrm{~g}$ of hydroxylamine hydrochloride in a small amount of water. Cautiously add $500 \mathrm{ml}$ of concentrated hydrochloric acid. Cool to $20^{\circ} \mathrm{C}$ and dilute to 1 liter with demineralized water.

Buffer Solution, pH 5.5. Dissolve $400 \mathrm{~g}$ of ammonium acetate in water. Add $350 \mathrm{ml}$ of concentrated ammonium hydroxide and dilute to 1 liter with demineralized water.

Iron Standard Solution. Dissolve $100.0 \mathrm{mg}$ of electrolytic iron in concentrated hydrochloric acid and dilute to 1 liter with demineralized water. Make serial dilutions of this stock solution to prepare a calibration curve.

Procedure. Clean all glassware. For this determination,
Table I. Determination of Iron in Ames City Water, Ames, Iowa

$\begin{array}{ccc}\text { Trial } & \begin{array}{c}\text { Iron found, } \\ \mathrm{mg} / \text { liter }\end{array} & \begin{array}{c}\text { Deviation } \\ \text { from mean }\end{array} \\ 1 & 0.157 & +0.001 \\ 2 & 0.155 & -0.001 \\ 3 & 0.156 & 0.000 \\ 4 & 0.158 & +0.002 \\ 5 & 0.158 & +0.002 \\ 6 & 0.156 & 0.000 \\ 7 & 0.153 & -0.003 \\ 8 & 0.154 & -0.002 \\ 9 & 0.156 & 0.000 \\ 10 & 0.156 & 0.000\end{array}$

Mean $=0.156 . \quad \sigma=0.005=3.20 \%$.

soaking in concentrated hydrochloric acid for several hours will produce satisfactory and reproducible results. Place $50.00 \mathrm{ml}$ of freshly drawn sample water in a $125-\mathrm{ml}$ Erlenmeyer flask. Add $1.00 \mathrm{ml}$ of acid reagent solution. Heat the solution on a hot plate and hold at the boiling point for ten minutes. Cool to $20^{\circ} \mathrm{C}$ and transfer the contents quantitatively to a $50-\mathrm{ml}$ volumetric fiask. Add $1.00 \mathrm{ml}$ of buffer solution and dilute to the mark with demineralized water. Mix thoroughly and allow 1 minute for full color development. Measure the absorbance at $562 \mathrm{~nm}$ against a calibration curve prepared from standard solutions treated in the same manner.

Interference Studies. A standard $1.00 \mathrm{mg} /$ liter Fe solution was used for all interference work, with varying concentrations of other species added. The criterion for an interference was an absorbance value varying more than $5 \%$ from the expected value.

\section{RESULTS}

Numerical results and statistical data are given in Tables I, II, and III concerning Ames City water, Hach Chemical Company well water, and interference studies.

Of copper, cobalt, calcium, magnesium, lead, silver, molybdenum, aluminum, nickel, zinc, arsenic, manganese, hexavalent chromium, and trivalent chromium, divalent cobalt and monovalent copper are the only metals other than iron which form colored species with ferrozine under the test conditions given above. At least $1000 \mathrm{mg} /$ liter of the alkali metals and the alkaline earths had no effect on the determination. Many heavy metals will react with ferrozine in competition with iron, but with the excess reagent used in the procedure above, this did not affect results.
Figure 3. Spectrophotometric titration of $4.62 \mathrm{mg}$ of ferrozine with $3.0 \times 10^{-3} M$ iron solution

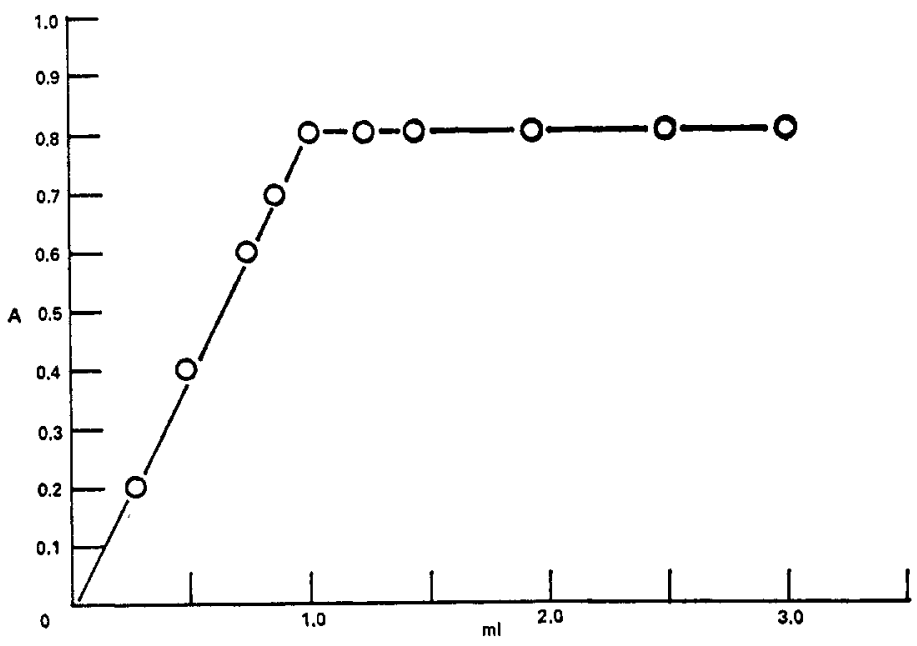


Figure 4. Effect of $\mathrm{pH}$ on formation of ferrous complex of ferrozine

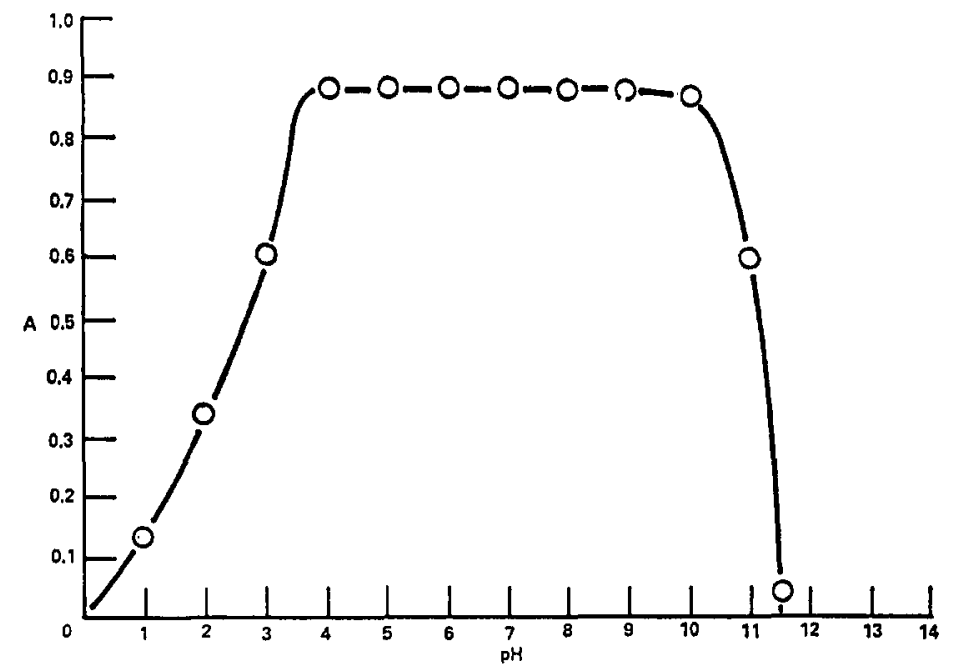

an immiscible organic liquid, such as one of the higher alcohols or nitrobenzene, it eliminates the compound from consideration as a reagent for completely automated analysis on a practical scale. To overcome this situation, the triazine was sulfonated. Infrared evidence suggests that both sulfonic acid groups occupy the 4 position on their respective rings.

Evidently the ferroin group may be formed from the pyridyl nitrogen and either the 2- or 4-triazine nitrogen. However, in the second case, steric hindrance would prevent three such structural isomers of the ligand from entering the octahedral coordination sphere of divalent iron. With the one structural isomer thus allowed, two optical isomers are possible as with any system of bidentate ligands in octahedral coordination. Because of the nonsymmetrical nature of the ligand, two positional isomers are possible for each optical isomer. On the basis of steric considerations only, the trans positional isomer would appear to be the preferred structure for both optical isomers.

Many methods have been published for the complete dissolution of a sample prior to the determination of iron. These are most useful when the sample contains organic matter or refractory iron oxides such as the ferrites. Suspended iron oxides in potable water are generally not difficult to dissolve. The digestion procedure given in this work proves quite adequate, having been checked with more rigorous methods (17).

The two major advantages of the use of ferrozine are its sensitivity and its low cost. Its molar absorptivity of 27,900 compares favorably with 22,600 for TPTZ, 22,143 for bathophenanthroline, and 11,100 for 1,10-phenanthroline. Interferences are at a minimum. The advantage of low cost is difficult to defend in a time of constantly fluctuating prices, but based on fundamental ease of manufacture, the cost of this reagent should be approximately one half the current price of 1,10-phenanthroline.

Received for review January 23, 1970. Accepted March 13, 1970. This material was presented in part before the 1970 Pittsburgh Conference on Analytical Chemistry and Applied Spectroscopy.

(17) J. Tetlow and A. Wilson, Analyst, 89, 442 (1964). 